\title{
Dexmedetomidine attenuates ventilator-induced lung injury in rats by up-regulating NLRC3
}

\author{
Benwang Zhang", Xiao Zhang", Qiujie Li, Fuguo Ma, Lixin Sun, Mingshan Wang \\ Department of Anesthesiology, Qingdao Municipal Hospital Affiliated to Qingdao University, Qingdao, China \\ Contributions: (I) Conception and design: L Sun, M Wang; (II) Administrative support: B Zhang, X Zhang; (III) Provision of study material or \\ patients: B Zhang, X Zhang; (IV) Collection and assembly of data: B Zhang, X Zhang; (V) Data analysis and interpretation: Q Li, F Ma; (VI) \\ Manuscript writing: All authors; (VII) Final approval of manuscript: All authors. \\ \#These authors contributed equally to this work. \\ Correspondence to: Lixin Sun. Department of Anesthesiology, Qingdao Municipal Hospital, No. 5 Donghai Middle Road, Qingdao, China. \\ Email: sunlixin1221@sina.com.
}

Background: Mechanical ventilation is a dispensable work in clinical treatment and rescue, and always caused of ventilator-induced lung injury (VILI). Dexmedetomidine is a clinical drug to prevent lung injury, but its mechanism still unclear.

Methods: Thirty-six SD rats were randomly divided into three groups: self-breathing control group (Group C), high tidal volume $\left(\mathrm{V}_{\mathrm{T}} 20 \mathrm{~mL} / \mathrm{kg}\right.$ ) group (Group $\mathrm{H}$ ) and high $\mathrm{V}_{\mathrm{T}}+$ dexmedetomidine group (Group DEX). Serum, lung tissue, bronchoalveolar lavage fluid (BALF) were collected after rats were sacrificed by anesthetic drug of pentobarbital sodium. The pathological changes of lung tissue were observed by hematoxylin and eosin stain (HE staining), and the lung injury score and wet/dry (W/D) ratio were tested to assess lung injury. The total protein level in BALF and contents of the interleukin-1 (IL-1 $\beta$ ), IL-18 in serum and BALF were detected by enzyme-linked immunosorbent assay (ELISA), the mRNA and protein expression level of NLR Family CARD Domain Containing 3 (NLRC3), NLR Family Pyrin Domain Containing 3 (NLRP3), Apoptosis associated speck-like protein containing a CARD domain (ASC) and caspase-1 were measured by qRT-PCR and Western Blotting respectively.

Results: Compared with Group C, VILI mode of Group H were success established because of lung injury score and W/D value increased. when compared with Group H, which were decreased significantly in Group $\operatorname{DEX}(\mathrm{P}<0.05)$, and the total protein level in BALF and the contents of IL-1 $\beta$, IL-18 in serum and BALF of Group DEX were reduced markedly $(\mathrm{P}<0.05)$, Besides the mRNA and protein expression of NLRP3, ASC and caspase-1 in lung tissue of Group DEX were lowered dramatically $(\mathrm{P}<0.05)$. However, mRNA and protein expression of NLRC3 in lung tissue of Group DEX were up-regulated observably $(\mathrm{P}<0.05)$.

Conclusions: This study demonstrates that NLRC3 is involved in the VILI of rats, and dexmedetomidine can attenuate the VILI in rats by up-regulating the expression level of NLRC3.

Keywords: Dexmedetomidine; ventilator-induced lung injury (VILI); NLRC3; NLRP3

Submitted Oct 15, 2019. Accepted for publication Jun 30, 2020.

doi: 10.21037/apm-19-375

View this article at: http://dx.doi.org/10.21037/apm-19-375

\section{Introduction}

As an important means of treatment and rescue, mechanical ventilation plays an indispensable role in clinical work and was used widely $(1,2)$, while positive pressure ventilation or anti-physiological ventilation was used in the application of mechanical ventilation, which may induce or aggravate lung injury, named ventilator-induced lung injury (VILI) (3). VILI includes of direct mechanical damage and indirect biological damage, and current researches divide mechanical 
damage into three parts: barotrauma, volutrauma and atelectrauma. Mechanical damage can mediate biotrauma through many pathways $(4,5)$, during which the lung cell wall was damaged directly by external mechanical force, which results in a large release of cytokines in the alveolars and circulatory system to lead local or systemic inflammatory reactions subsequently (6). The mainly pathophysiological changes of VILI include the alveolar structural destruction, the increased pulmonary vascular permeability, the activation of inflammatory cells and inflammatory factors and the imbalance of oxidation and antioxidation, etc. (7). VILI has become one of the most serious complications of mechanical ventilation (8). Therefore, the prevention and treatment of VILI have become importantly and necessarily.

During mechanical ventilation, the external mechanical force will activate NLRP3 inflammasome, which is a member of the nucleotide oligomerization domain-like receptor (NLR) family. NLR family composed of NLRP3, an apoptosisassociated speck-like protein containing a CARD domain (ASC), and pro-caspase-1 (9). The activation of NLRP3 inflammasome releases the proinflammatory cytokines of interleukin (IL)-1 $\beta$, IL-18 and finally induces lung and body inflammatory response (10). NLRC3, like NLRP3, also belongs to the NLR family. Its main structures include a nucleotide-binding oligomerization domain (NACHT) in the middle, a C-terminal leucine-rich repeat domain (LRR) on one side and an $\mathrm{N}$-terminal cysteine aspartase recruitment domain (CARD) on the other side (11). Unlike NLRP3, NLRC3 does not participate in the composition of the inflammasome and, contrary to NLRP3, plays a negative regulatory role in inflammatory responses $(12,13)$. However, the relationship between NLRC3 and VILI in rats still not clarified.

Dexmedetomidine, a fat-soluble alpha2 adrenergic receptor agonist, was first used in clinical work as a sedative and analgesic drug in 1999 (14). Because dexmedetomidine has a weak inhibitory effect on the respiratory system and circulatory system, it is mainly used for sedation and analgesia in the intensive care unit, and as an anesthesia adjuvant for a perioperative period (15). The study found that dexmedetomidine has protective effects on a variety of organs, including lung. Dexmedetomidine can downregulate high mobility protein 1 (HMGB1), reduce the expression of TNF- $\alpha$, IL- 1 and IL- 6 to attenuate inflammatory response. Kim et al. (16) found that dexmedetomidine can inhibit the inflammatory response by blocking the TLR-4/NF- $\mathrm{BB}$ pathway. The research by Meng et al. (17) showed that infusion of dexmedetomidine can improve lung oxygenation in patients with restrictive lung disease and morbid obesity. At the same time, some studies have pointed out that dexmedetomidine can alleviate lipopolysaccharide-induced acute lung injury by inhibiting the activation of NLRP3 inflammasome (18).

Although previous studies have shown that dexmedetomidine can alleviate lung injury, its specific mechanism for lung protection is not yet perfect clarified. The purpose of this study is to discuss whether NLRC3 is involved in the process of VILI, and whether the lung protection mechanism of dexmedetomidine is related with NLRC3. We present the following article in accordance with the ARRIVE reporting checklist (available at http:// dx.doi.org/10.21037/apm-19-375).

\section{Methods}

This study was approved by The Ethics Committee of Qingdao Municipal Hospital affiliated to Qingdao University in compliance with guidelines for the care and use of animals. Animals were treated in accordance with Guide for the Care and Use of Laboratory Animals (8th edition, National Academies Press). Experiments were performed under a project license (NO. 2018033).

\section{Experimental animal and grouping}

Thirty-six clean male SD rats, 240-260 g, 8 weeks old, were provided by Pengyue Experimental Unit (Jinan, China), with the animal certificate number SCXK (Shandong) 20140007. At temperature of $23-26^{\circ} \mathrm{C}$, all rats were free to diet for one week in SPF environment, and divided which into 3 groups by random number labeling method: selfbreathing control group (Group C), high tidal volume $\left(\mathrm{V}_{\mathrm{T}}\right)$ group (Group $\left.\mathrm{H}\right)$, high $\mathrm{V}_{\mathrm{T}}+$ dexmedetomidine group (Group DEX), 12 rats per group.

\section{Instruments and reagents}

Small animal ventilator (R415, Ruiwode Life Technology Co., Ltd, China), BCA protein concentration kit ( P0010, Biyuntian Biotechnology Co., Ltd., China), IL-1 $\beta$ and IL-18 ELISA kit (JW-E14034, Jiwei Biological Technology Co., Ltd., China), PCR instrument (A600, Mio Instrument Co., Ltd., China), NanoDrop spectrophotometer (Nanodrop one, Thermo fisher, USA), Ultraviolet analyzer (JY0S-3D, Junyi Oriental Electrophoresis Equipment Co., Ltd., China), Real-time PCR instrument (Applied Biosystems, USA), Trizol RNA Extraction Reagent 
(B511311, Sangon Biochemical Technology Co., Ltd, China), PrimeScriptTM RT reagent Kit with gDNA Eraserc (RR047, TaKaRa, Japan), SYBR ${ }^{\circledR}$ Premix Ex TaqTM II ( RR820A,TaKaRa, Japan), the primer of NLRC3, NLRP3, ASC, caspase-1 and internal reference $\beta$-actin (GENEWIZ, USA), NLRC3, NLRP3, ASC, caspase- 1 and internal reference $\beta$-actin Primary antibody (ARG65683, Arigo Biotechnology Co., Ltd, China), goat anti-rabbit secondary antibody ( ab182016, Abcam company., Ltd, USA).

\section{Animal models}

All rats were fasted for 8 hours before the experiment, and then were intraperitoneally injected with $3 \%$ pentobarbital sodium $(50 \mathrm{mg} / \mathrm{kg})$. The rats were fixed on the test bench in a supine position after anesthesia, and tracheotomy intubation was performed after neck skin preparation and disinfection. Arterial blood pressure was monitored by a right carotid artery, and venous access was established by a right jugular vein. The anal temperature of rats was maintained at $37-38{ }^{\circ} \mathrm{C}$ by an animal insulation blanket. The method of reference (19) was used to establish the VILI model of rats. After successful tracheotomy and intubation, the rats in the Group $\mathrm{C}$ maintained spontaneous respiration; rats in the Group $\mathrm{H}$ and Group DEX were injected with rocuronium $0.1 \mathrm{mg} / \mathrm{kg}$ via the right jugular vein, and then connected to the small animal ventilator for mechanical ventilation for 4 hours after the spontaneous respiration disappeared. Rats in the Group DEX were intraperitoneally injected with dexmedetomidine $50 \mu \mathrm{g} / \mathrm{kg}$ 30 minutes before mechanical ventilation, and rats in the Group C and Group H were intraperitoneally injected with the same amount of normal saline 30 minutes before mechanical ventilation. Mechanical ventilation parameters were set as follows: $V_{\mathrm{T}}$ was set to $20 \mathrm{~mL} / \mathrm{kg}$, the suction and respiration ratio (I:E) was $1: 1$, the respiratory rate (f) was 80 times/min, the oxygen concentration $\left(\mathrm{FiO}_{2}\right)$ was $21 \%$.

\section{Specimen collection}

After 4 hours of mechanical ventilation, $5 \mathrm{~mL}$ blood was extracted from the right carotid artery, centrifuged at $4{ }^{\circ} \mathrm{C}$ and 3,000 r/min for 10 minutes, and then the supernatant was collected and stored at $-80^{\circ} \mathrm{C}$. After that, the rats were sacrificed by intraperitoneal injection of pentobarbital sodium $80 \mathrm{mg} / \mathrm{kg}$. The lung tissue of rats was quickly removed, the right lung was ligated. The upper lobe of the right lung was placed in a $5 \mathrm{~mL}$ centrifuge tube for examination, the middle lobe of the right lung was placed in $4 \%$ paraformaldehyde for examination, and the he lower lobe of the right lung was preserved in liquid nitrogen for examination. The left lung of rats was lavage with $5 \mathrm{~mL}$ precooled phosphate buffer (PBS) through endotracheal tube for 3 times, $5 \mathrm{~mL}$ bronchoalveolar lavage fluid (BALF) was collected, then, centrifuged at 3,000 r/min and $4{ }^{\circ} \mathrm{C}$ for $15 \mathrm{~min}$, supernatant was collected and stored at $-80^{\circ} \mathrm{C}$ for experiments.

\section{Pathological evaluation of lung tissue and lung injury score}

The middle lobe of the right lung was taken, fixed with $4 \%$ paraformaldehyde for 24 hours, embedded in paraffin, sectioned, stained with hematoxylin and eosin (HE), and observed under a light microscope. Lung injury score was performed by the method of reference (20). The scoring criteria included pulmonary edema, bleeding, neutrophil infiltration and small airway injury, each of which was rated as $0-4$ points according to the severity of the lesion (0: no lesion or very mild disease; 1 : mild lesion; 2 : moderate lesions; 3: severe lesions; 4: extremely severe lesions). The total score of 4 items is the lung injury score.

\section{Determination of wet/dry (W/D) ratio of lung tissue}

The upper lobe of the right lung was taken and the surface moisture was absorbed by filter paper to weigh wet mass. Then it was dried in an electric drying box at $80^{\circ} \mathrm{C}$ to a constant weight. The dry weight was weighed and the W/D of lung tissue was calculated.

\section{Determination of total protein in BALF}

The total protein content in BALF of rats was determined by BCA method according to the procedure described in the instructions of BCA Protein Concentration Kit.

\section{Determination of cytokines in serum and BALF}

The IL-1 $\beta$ and IL-18 levels in serum and BALF of rats were determined by ELISA according to the procedure described 
Table 1 The primer sequence of NLRC3, NLRP3, ASC, caspase- 1 and internal reference $\beta$-actin

\begin{tabular}{lll}
\hline Gene name & Forward primer $\left(5^{\prime}-3^{\prime}\right)$ & Reverse primer $\left(5^{\prime}-3^{\prime}\right)$ \\
\hline NLRC3 & CAGATTGGTAACAAAGAGCCA & CGTTCGGTTTATCTTCAGAGCA \\
NLRP3 & CAGGCGATCAACAGGCGAGAC & AGAGATATCCCAGCAAACCTATCCA \\
ASC & TGTGCTTAGAGACATGGGCATACAG & GCCATACAGAGCATCCAGCAA \\
Caspase-1 & ACTCGTACACGTCTTGCCCTCA & CTGGGCAGGCAGCAAATTC \\
$\beta$-actin & TCCTGTGGCATCCATGAAACT & GAAGCATTTGCGGTGCACGAT \\
\hline
\end{tabular}

in the instructions of ELISA Kit.

\section{$q R T-P C R$}

Partial tissues of the lower lobe of the right lung were taken, and the total RNA of lung tissues was extracted by Trizol one-step method after liquid nitrogen grinding according to the procedure described in the instructions. The concentration and purity of RNA were determined by ultraviolet absorption assay. The mRNA expressions of NLRC3, NLRP3, ASC and caspase-1 were determined by qRT-PCR, cDNA was synthesized by cDNA synthesis kit, and the mRNA of NLRC3, NLRP3, ASC and caspase-1 were amplified by ABI 7500 fluorescence quantitative PCR instrument. The primer sequences of NLRC3, NLRP3, ASC, caspase- 1 and internal reference $\beta$-actin (Table 1). The reaction system of qRT-PCR was as follows: predenaturation at $95{ }^{\circ} \mathrm{C}, 30$ seconds, denaturation at $95{ }^{\circ} \mathrm{C}$, 5 seconds, annealing at $60^{\circ} \mathrm{C}, 34$ seconds, a total of 40 cycles. The differences between groups were compared by $2^{-\Delta \Delta \mathrm{Ct}}(\Delta \mathrm{Ct}$ = target gene $\mathrm{Ct}$ value - internal reference $\mathrm{Ct}$ value), using the instrument's own software to do data analysis.

\section{Western blotting}

Partial tissue of the lower lobe of the right lung was cut into the size of rice grains and ground in a pre-cooled mortar. Tissue cell lysate was added. After 30 minutes on ice, the supernatant was centrifuged at $4{ }^{\circ} \mathrm{C}$ and $12,000 \mathrm{r} / \mathrm{min}$ for 15 minutes and the protein concentration was determined by BCA method. The total protein samples were taken out from the refrigerator at $-80{ }^{\circ} \mathrm{C}$. After dissolution, $5 \times$ loading buffer was added and reacted at $95{ }^{\circ} \mathrm{C}$ for 10 minutes. The membrane was transferred by SDS-PAGE and PVDF membrane wet transfer method under the conditions of $130 \mathrm{~mA}$ current, $60 \mathrm{~V}$ voltage and
60 minutes membrane transfer time. After sealing in the sealant for 1 hour, NLRC3 primary antibody $(1: 1,000)$, NLRP3 primary antibody $(1: 1,000)$, ASC primary antibody $(1: 1,000)$, caspase- 1 primary antibody $(1: 1,000)$ and internal reference $\beta$-actin primary antibody $(1: 5,000)$ were added and incubated overnight at $4{ }^{\circ} \mathrm{C}$. Then the solution was washed 3 times with $1 \times$ TBST, 10 minutes each time. The primary antibody membrane was placed into goat antirabbit secondary antibody $(1: 5,000)$ and incubated at room temperature for 1 hour. Then the solution was washed 3 times with $1 \times$ TBST, 10 minutes each time. Using IMAGE J software (NIH, USA) to scan the gray value of protein bands, the content of target protein was expressed by the ratio of the gray value of protein bands to the gray value of internal reference $\beta$-actin bands.

\section{Statistical analysis}

SPSS19.0 was used for statistical analysis. The measurement data of normal distribution were expressed as mean \pm standard deviation $(\bar{x} \pm S)$, and one-way ANOVA analysis was conducted for comparison between groups. $\mathrm{P}<0.05$ was considered statistically significant.

\section{Results}

\section{Dexmedetomidine alleviates VILI}

Firstly, under light microscope, we observed that the alveolar structure of rats in Group C was normal, the alveolar wall was continuous, and the boundary was clear. In Group $\mathrm{H}$, alveolar cavity fusion, alveolar wall thickening and rupture, pulmonary interstitial edema and a large number of inflammatory cell infiltration were observed. In Group DEX, alveolar injury was milder than that in Group H, slight edema was observed in the pulmonary interstitium, and a small amount of inflammatory cells 


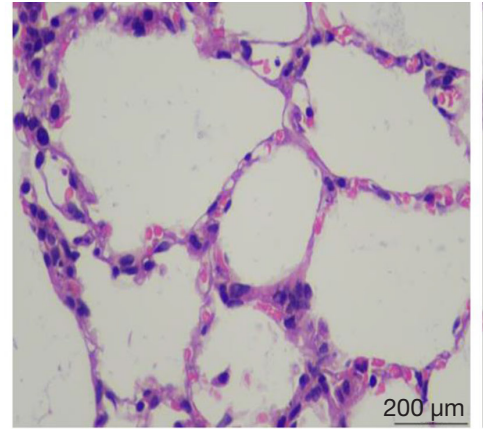

Group C

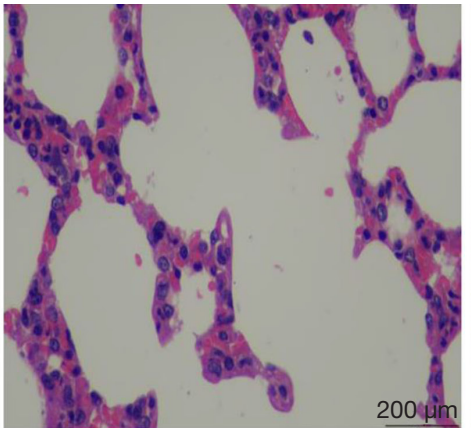

Group H

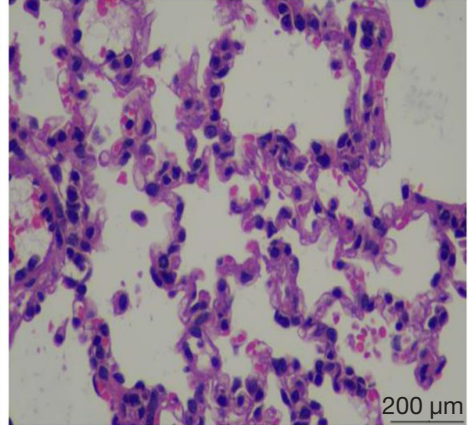

Group DEX

Figure 1 Pathological changes of lung tissue in rats of different groups. Group C: self-breathing control group, Group H: high tidal volume (VT) group $\left(V_{\mathrm{T}}\right.$ is $\left.20 \mathrm{~mL} / \mathrm{kg}\right)$, Group DEX: high $\mathrm{V}_{\mathrm{T}}+$ dexmedetomidine group $\left(\mathrm{V}_{\mathrm{T}}\right.$ is $\left.20 \mathrm{~mL} / \mathrm{kg}\right)$. Rats in Group DEX received $50 \mu \mathrm{gg} / \mathrm{kg}$ dexmedetomidine by intraperitoneal injection 30 minutes before mechanical ventilation, and rats in Group $\mathrm{C}$ and $\mathrm{Group} \mathrm{H}$ received equal amount of normal saline by intraperitoneal injection 30 minutes before mechanical ventilation. Alveolar structure of different group were observed under light microscope with 400× after HE stain. DEX, Dexmedetomidine,

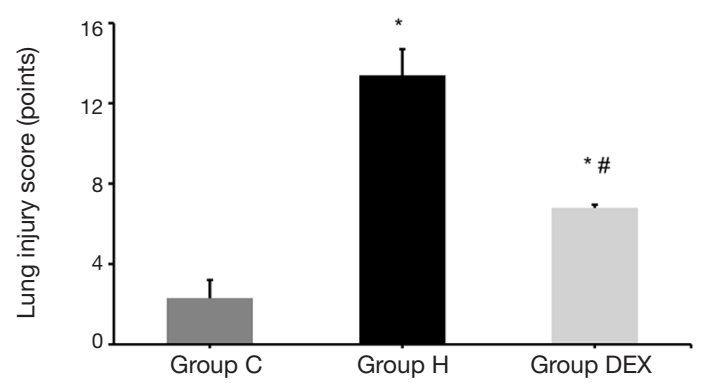

Figure 2 Lung injury scores in rats of different groups. Group C: self-breathing control group, Group H: high tidal volume $\left(\mathrm{V}_{\mathrm{T}}\right)$ group $\left(\mathrm{V}_{\mathrm{T}}\right.$ is $\left.20 \mathrm{~mL} / \mathrm{kg}\right)$, Group DEX: high $\mathrm{V}_{\mathrm{T}}+$ dexmedetomidine group $\left(\mathrm{V}_{\mathrm{T}}\right.$ is $\left.20 \mathrm{~mL} / \mathrm{kg}\right) .{ }^{*}, \mathrm{P}<0.01$ vs. Group $\mathrm{C}$; \#, $\mathrm{P}<0.05$ vs. Group H.

exuded from alveolar cavity (Figure 1).

\section{Dexmedetomidine decreases lung injury score to prevent VILI}

Next, lung injury score was measured in different groups. We discovered that compared with Group C, the lung injury scores of Group H and Group DEX were increased nearly 6 folds $(\mathrm{P}<0.01)$, and compared with Group H, the lung injury score of Group DEX was largely reduced
$(\mathrm{P}<0.05$, Figure 2).

Dexmedetomidine reduces W/D of lung tissue to alleviate VILI

Latterly, the effect of dexmedetomidine on W/D of lung tissue was checked. Compared with Group C, the W/D of Group $\mathrm{H}$ and Group DEX were significantly increased $(\mathrm{P}<0.05)$. Compared with Group H, the W/D of Group DEX was decreased 1.4 folds obviously $(\mathrm{P}<0.05$, Figure 3$)$.

\section{Dexmedetomidine down-regulates the content of total protein in BALF to prevent VILI}

And compared with Group C, the total protein content in BALF of Group $\mathrm{H}$ and Group DEX were increased $(\mathrm{P}<0.05)$. Compared with Group $\mathrm{H}$, the total protein content in BALF of Group DEX was also significantly reduced $(\mathrm{P}<0.05$, Figure 4$)$.

\section{Dexmedetomidine decreases cytokines in serum and BALF to inbibit VILI}

Besides, total protein in BALF were measured by ELISA kits, we found that compared with Group C, the levels of IL-1 $\beta$ and IL-18 in serum and BALF of Group H and Group DEX were obviously increased $(\mathrm{P}<0.05)$. Compared 


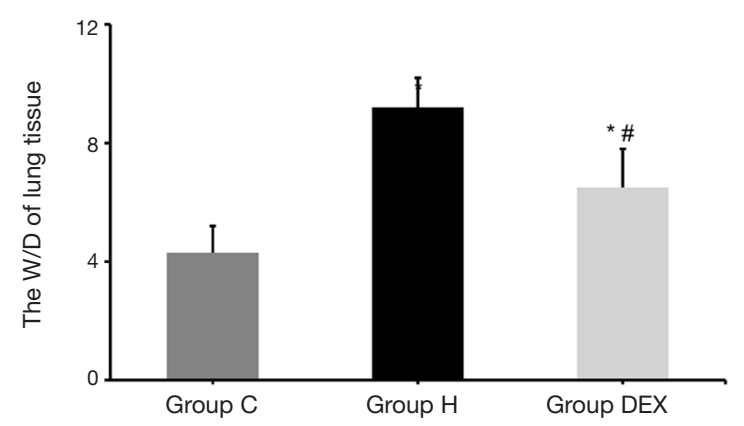

Figure $3 \mathrm{~W} / \mathrm{D}$ of lung tissue in rats of different groups. Group C: self-breathing control group, Group $\mathrm{H}$ : high tidal volume $\left(\mathrm{V}_{\mathrm{T}}\right)$ group ( $\mathrm{V}_{\mathrm{T}}$ is $20 \mathrm{~mL} / \mathrm{kg}$ ), Group DEX: high $\mathrm{V}_{\mathrm{T}}+$ dexmedetomidine group $\left(\mathrm{V}_{\mathrm{T}}\right.$ is $\left.20 \mathrm{~mL} / \mathrm{kg}\right)$. *, $\mathrm{P}<0.05$ vs. Group $\mathrm{C}$; ${ }^{*}, \mathrm{P}<0.05$ vs. Group H. W/D, Wet/dry ratio.

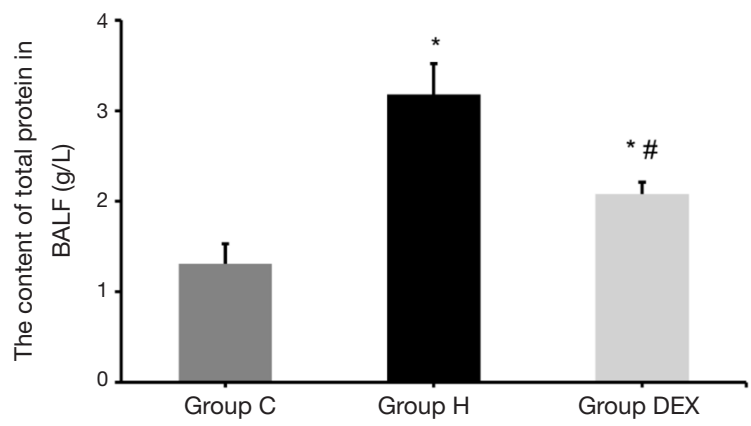

Figure 4 The content of total protein in BALF in rats of different groups. Group C: self-breathing control group, Group H: high tidal volume $\left(\mathrm{V}_{\mathrm{T}}\right)$ group $\left(\mathrm{V}_{\mathrm{T}}\right.$ is $\left.20 \mathrm{~mL} / \mathrm{kg}\right)$, Group DEX: high $\mathrm{V}_{\mathrm{T}}+$ dexmedetomidine group $\left(\mathrm{V}_{\mathrm{T}}\right.$ is $\left.20 \mathrm{~mL} / \mathrm{kg}\right)$. *, $\mathrm{P}<0.05$ vs. Group $\mathrm{C}$; \#, $\mathrm{P}<0.05$ vs. Group H. BALF, bronchoalveolar lavage fluid.

with Group $\mathrm{H}$, the levels of IL- $1 \beta$ and IL-18 in serum and BALF of Group DEX were significantly decreased $(\mathrm{P}<0.05$, Figure 5).

\section{Dexmedetomidine reduces NLRP3, ASC, caspase-1 mRNA level, and increases NLRC 3 to prevent VILI}

Moreover, qRT-PCR results showed that Compared with Group C, the mRNA expression of NLRC3 in lung tissues of Group $\mathrm{H}$ was decreased $(\mathrm{P}<0.01)$, while the mRNA expression of NLRC3 in lung tissues of Group DEX was increased $(\mathrm{P}<0.01)$, and the mRNA expression of NLRP3, ASC and caspase- 1 in lung tissue of Group $\mathrm{H}$ and Group DEX were significantly increased $(\mathrm{P}<0.05)$. Compared with
Group H, the mRNA expression of NLRC3 in lung tissues of Group DEX was increased, the mRNA expression of NLRP3, ASC and caspase-1 in lung tissue of Group DEX were decreased $(\mathrm{P}<0.05$, Figure 6).

\section{Dexmedetomidine reduces NLRP3, ASC, caspase-1 mRNA protein level, and increases NLRC3 to alleviate VILI}

At last, Western blotting results in consistence results with qRT-PCR. Compared with Group C, the protein expression of NLRC3 in lung tissues of Group H was decreased $(\mathrm{P}<0.01)$, while the protein expression of NLRC3 in lung tissues of Group DEX was increased $(\mathrm{P}<0.01)$, and the protein expression of NLRP3, ASC and caspase- 1 in lung tissue of Group $\mathrm{H}$ and Group DEX were increased $(\mathrm{P}<0.05)$. Compared with Group $\mathrm{H}$, the protein expression of NLRC3 in lung tissues of Group DEX was increased, the protein expression of NLRP3, ASC and caspase-1 in lung tissue of Group DEX were decreased $(\mathrm{P}<0.05$, Figure 7).

\section{Discussion}

Mechanical ventilation plays an irreplaceable role in clinical work and functions as an effective means for life support and treatment, but its application in VILI will cause pulmonary complications. VILI is wildly used in people with lung disease. VILI deteriorates into acute respiratory distress syndrome (ARDS) or even result in death of patients was due to alveolar collapse or gas exchange disorder (21). In addition, with the aggravation of pulmonary inflammation, some inflammatory cytokines can spread to other organs of the body through the circulatory system, which leading to the outbreak of whole-body cascades of inflammation to endanger the health and safety of patients. Therefore, it has great clinical significance to explore the mechanism and preventive measures of VILI. VILI model of rats were established by referring to Wu reported methods (19). After mechanical ventilation with VT of $20 \mathrm{~mL} / \mathrm{kg}$ for 4 hours in Group $\mathrm{H}$, the phenomenon of alveolar cavity fused, alveolar wall thickened and fractured, pulmonary interstitial edema, and a large number of inflammatory cells infiltrated in the alveolar cavity were observed. Lung injury score, W/ $\mathrm{D}$ of lung tissue and total protein content of BALF were significantly higher than those in Group C, indicating that VILI model of rats has been success established.

NLRP3 inflammasome belongs to NLR family, which is a type of pattern recognition receptor (PRR) in cytoplasm (22). Studies have shown that NLR, includes 
A

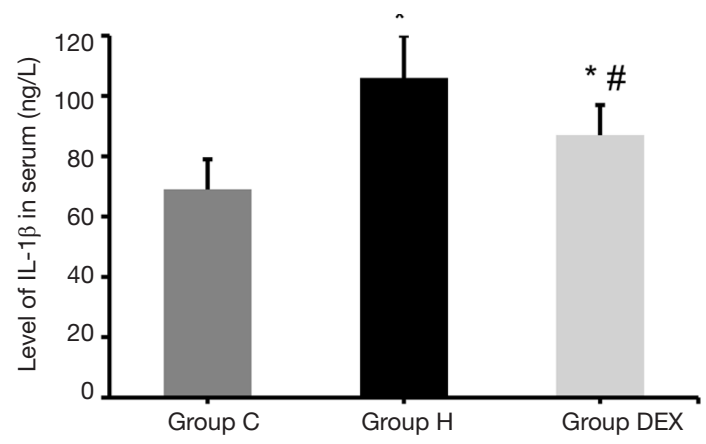

C

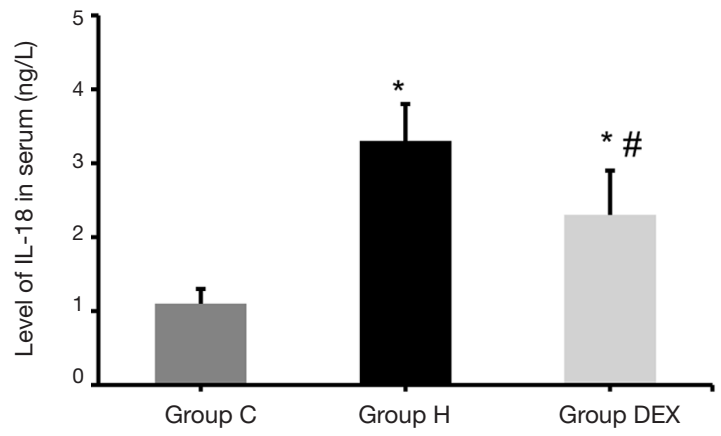

B

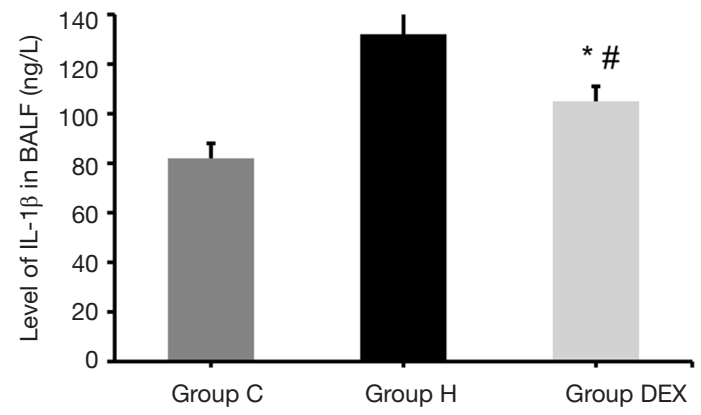

D

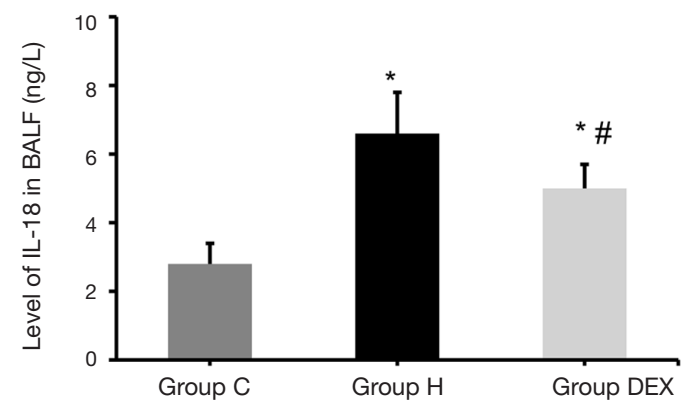

Figure 5 Levels of cytokines in serum and BALF in rats of different groups. (A) IL-1 $\beta$ level in serum in three groups of rats; (B) IL-1 $1 \beta$ level in BALF; (C) IL-18 level in serum; (D) IL-18 level in BALF in three groups of rats. Group C: self-breathing control group, Group H: high tidal volume $\left(\mathrm{V}_{\mathrm{T}}\right)$ group $\left(\mathrm{V}_{\mathrm{T}}\right.$ is $\left.20 \mathrm{~mL} / \mathrm{kg}\right)$, Group DEX: high $\mathrm{V}_{\mathrm{T}}+$ dexmedetomidine group $\left(\mathrm{V}_{\mathrm{T}}\right.$ is $\left.20 \mathrm{~mL} / \mathrm{kg}\right)$. *, $\mathrm{P}<0.05$ vs. Group C; , $\mathrm{P}<0.05$ vs. Group H. BALF, bronchoalveolar lavage fluid; IL-1 $\beta$, interleukin-1 $\beta ;$ IL-18, interleukin-18.

NLRP3, apoptosis-associated speck-like protein containing a CARD domain (ASC) and pro-caspase-1, is mainly expressed in macrophages, lymphocytes (23). During mechanical ventilation treatment, mechanical force acts on the lungs, causing direct mechanical damage to alveolar cells due to the accumulation of reactive oxygen species (ROS) in the mitochondria of alveolar macrophages (24). NLRP3 exposes its effect domain through oligomerization of NOD domain to collect ASC after sensing ROS and other stimulation. ASC is a kind of adaptor protein containing CARD and pyrin domain (PYD). When ASC is recruited, its PYD combines to the N-terminus of NLRP3 and its CARD binds pro-caspase- 1 to form the NLRP3 inflammasome (25-27). After the activation of NLRP3 inflammasome, pro-caspase- 1 cleaved itself into caspase- 1 initiates a cascade inflammatory response mediated by the maturation and release of IL- $1 \beta$ and IL-18 protein expressions of NLRP3. ASC and casepase- 1 in the lung tissues of rats in Group H were significantly increased compared with those in Group C, and the contents of IL-1 $\beta$ and IL-18 in serum and BALF of rats in Group H had the similar trend with above. These results suggest that NLRP3 inflammasome is involved in the process of VILI activated by it and the downstream pro-inflammatory cytokines of IL- $1 \beta$ and IL-18 are matured and released to induce the pulmonary inflammatory response eventually. NLRC3 also belongs to the NLR family, which exists in the cytoplasm and wildly discovered in macrophages, lymphocytes, epithelial cells and other immune cell (3,28-30). Unlike NLRP3, NLRC3 plays a negative regulatory role in inflammatory response. Previous studies (31) have shown that NLRC3 can monitor the production of inflammatory cytokines in macrophages. NLRC3 inhibits TLR4/NF$\kappa \mathrm{B}$ pathway activation, by reducing the level of TRAF6, and affects the transmission of inflammatory signals in the downstream of TLR4/NF- $\mathrm{KB}$ pathway by inhibited the 
A

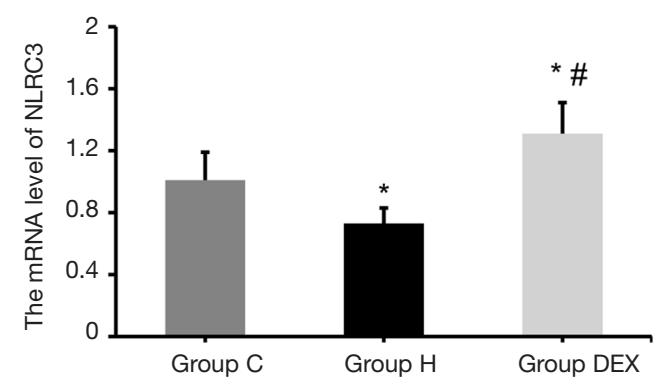

C

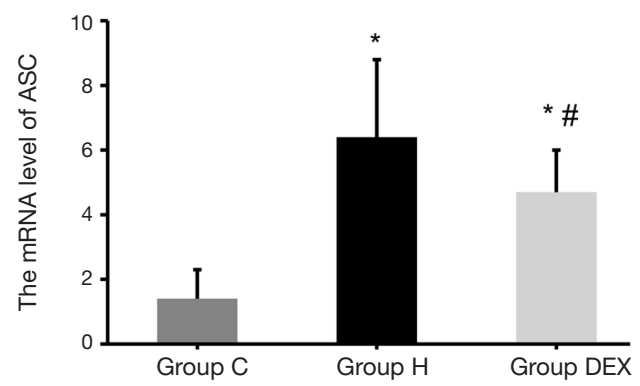

B
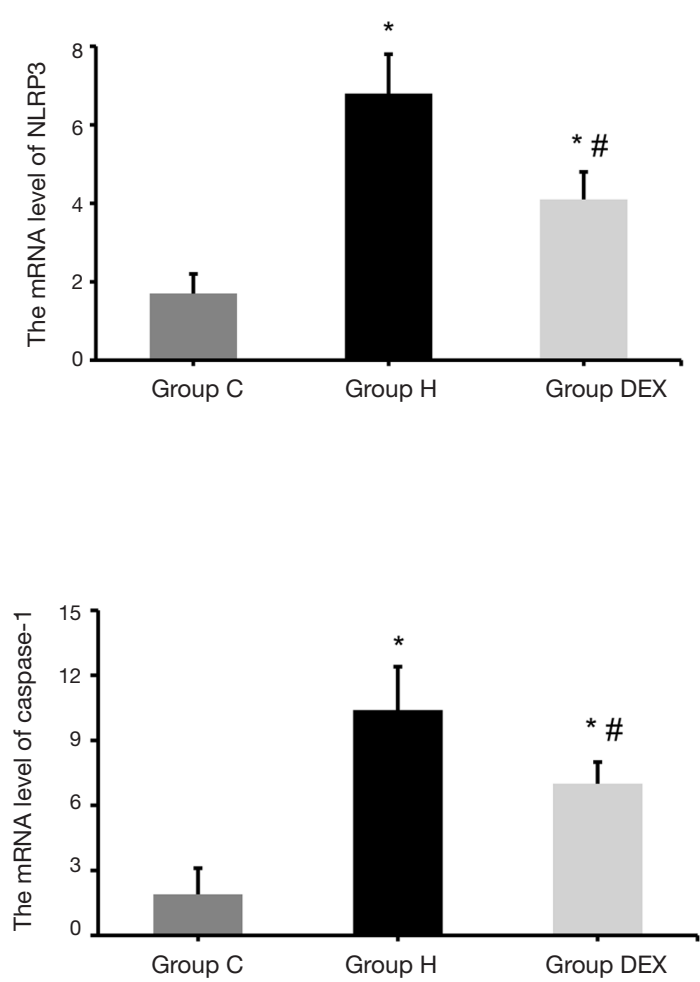

Figure 6 The mRNA expression of NLRC3, NLRP3, ASC and caspase-1 in lung tissue in rats of different groups. (A) The mRNA expression level of NLRC3 in three groups of rats; (B) the mRNA expression level of NLRP3; (C) the mRNA expression level of ASC; (D) the mRNA expression level of caspase-1. Group C: self-breathing control group, Group H: high tidal volume $\left(V_{T}\right)$ group $\left(V_{T}\right.$ is $\left.20 \mathrm{~mL} / \mathrm{kg}\right)$, Group DEX: high $\mathrm{V}_{\mathrm{T}}+$ dexmedetomidine group $\left(\mathrm{V}_{\mathrm{T}}\right.$ is $\left.20 \mathrm{~mL} / \mathrm{kg}\right)$. *, $\mathrm{P}<0.05$ vs. Group C; ${ }^{*}, \mathrm{P}<0.05$ vs. Group H. NLRC3, NLR Family CARD Domain Containing 3; NLRP3, NLR Family Pyrin Domain Containing 3; ASC, apoptosis associated speck-like protein containing a CARD domain.

phosphorylation of NF-kB. Besides, further studies $(32,33)$ showed that NLRC3 binds to Stimulator of Interferon Inducible Genes (STING) to affect the interaction between STING and TANK-binding kinase 1 (TBK1) and the production of downstream type I interferon (IFN), and then inhibits the innate immune response of STING to viral DNA, cytosolic DNA or c-di-GMP. In addition, NLRC3 can bind to pro-caspase-1 in NLRP3 inflammasome, which affects the interaction between ASC and pro-caspase- 1 and then inhibits the activation of NLRP3 inflammasome (34). There is still no relevant study on whether NLRC3 is involved in the process of VILI in rats. Our results showed that the mRNA and protein expressions of NLRC 3 in the lung tissues in rats of Group $\mathrm{H}$ were significantly downregulated compared with Group C. These results suggest that NLRC3 is involved in the process of VILI and the down-regulated expression of NLRC3 can induce or aggravate VILI occurrence in rats.
Dexmedetomidine, a safe alpha-2 adrenergic receptor agonist, is widely used as a sedative in clinical practice. In recent years, studies have found that dexmedetomidine plays a certain protective effect on the lungs and it can reduce acute lung injury caused by sepsis in rats by down-regulating the RAGE pathway signal (35); Dexmedetomidine inhibits the expression of IL-17, and decreases its effect on NF- $\mathrm{KB}$ signaling pathway activation, to inhibit inflammatory response (36). Moreover, studies showed that it can negatively regulate the inflammatory response through the TLR4/NF- $\mathrm{BB}$ signaling pathway mediated by HMGB1 and PI3K/Akt/mTOR signaling pathway $(37,38)$. Besides, Dexmedetomidine may also reduce LPS-induced acute lung injury by inhibiting the activation of NLRP3 inflammasome (18), However, it inhibits the activation of NLRP3 inflammasome through which pathway remains unclear. Our results showed that the pathological injury of lung tissue and the W/D of lung 
A
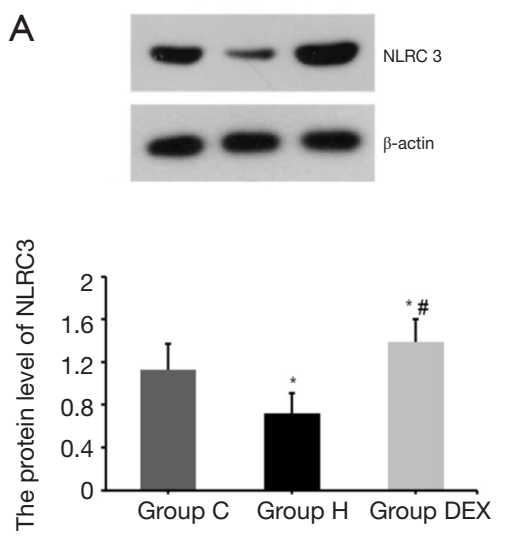

C
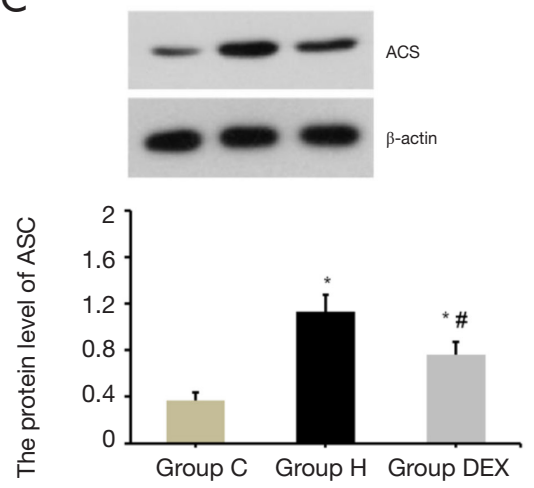

B
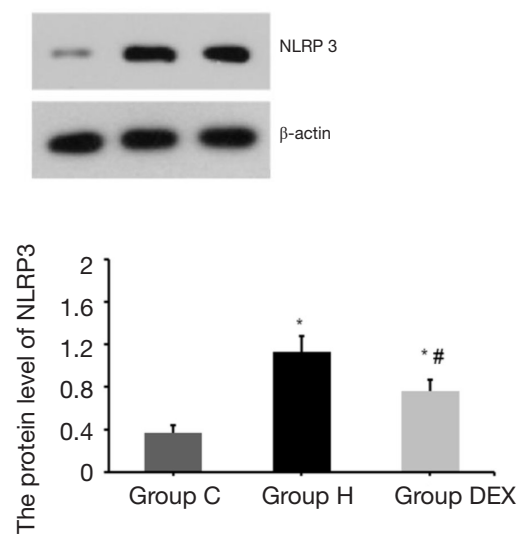

D

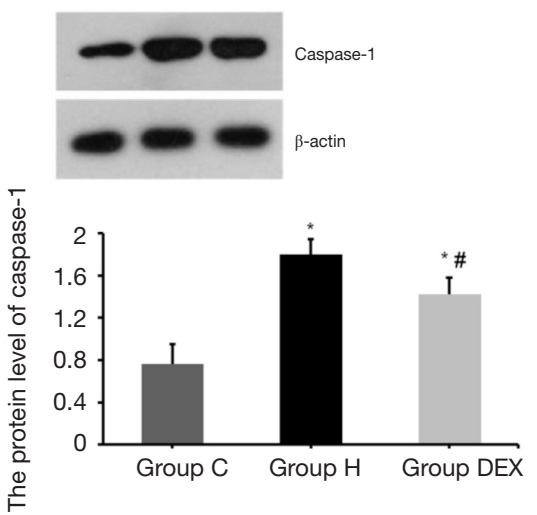

Figure 7 The protein expression of NLRC3, NLRP3, ASC and caspase-1 in lung tissue in rats of different groups. (A) The protein expression level of NLRC3 in three groups of rats; (B) the protein expression level of NLRP3; (C) the protein expression level of ASC; (D) the protein expression level of caspase-1. Group C: self-breathing control group, Group H: high tidal volume $\left(\mathrm{V}_{\mathrm{T}}\right)$ group $\left(\mathrm{V}_{\mathrm{T}}\right.$ is $\left.20 \mathrm{~mL} / \mathrm{kg}\right)$, Group DEX: high $\mathrm{V}_{\mathrm{T}}+$ dexmedetomidine group $\left(\mathrm{V}_{\mathrm{T}}\right.$ is $\left.20 \mathrm{~mL} / \mathrm{kg}\right)$. *, $\mathrm{P}<0.05$ vs. Group $\mathrm{C}$; ${ }^{*}, \mathrm{P}<0.05$ vs. Group H. NLRC3, NLR Family CARD Domain Containing 3; NLRP3, NLR Family Pyrin Domain Containing 3; ASC, apoptosis associated speck-like protein containing a CARD domain.

tissue or total protein content in BALF in Group DEX were obviously reduced in contrast with Group $\mathrm{H}$, these results demonstrate that dexmedetomidine can reduce VILI in rats. Meanwhile, the mRNA and protein expressions of NLRC3 in Group DEX was up-regulated compared with that in Group H. compared with Group H, the mRNA and protein expressions of NLRP3, ASC and caspase- 1 in Group DEX were down-regulated, and the level of proinflammatory cytokines such as IL- $1 \beta$ and IL-18 in serum and BALF were largely reduced also. these results suggest that dexmedetomidine can reduce inflammation and inhibit VILI in rats by up-regulating the expression of NLRC3, and the mechanism may be related to NLRC3 inhibiting the activation of NLRP3 inflammasome to block the maturation and release of pro-inflammatory cytokines such as IL-1 $\beta$ and IL-18. However, the study still not clarified the specific mechanism that dexmedetomidine regulates NLRC3, nor the necessary association between NLRC3 and NLRP3 inflammasome, which present the limitations of the study. Therefore, in future studies, we hope that we can in-depth study of the role of NLRC3 in VILI with cell experiments, and explore the specific mechanism of dexmedetomidine on NLRC3.

\section{Conclusions}

The study demonstrates that NLRC3 is involved in the process of VILI in rats. Dexmedetomidine can alleviate VILI occurrence by up-regulating the expression of NLRC3, and its mechanism may be result of NLRC3 
inhibits the activation of NLRP3 inflammasome and blocks the maturation and release of pro-inflammatory cytokines of IL-1 $\beta$ and IL-18.

\section{Acknowledgments}

Funding: None.

\section{Footnote}

Reporting Checklist: The authors have completed the ARRIVE Reporting Checklist. Available at http://dx.doi. org/10.21037/apm-19-375

Data Sharing Statement: Available at http://dx.doi. org/10.21037/apm-19-375

Conflicts of Interest: All authors have completed the ICMJE uniform disclosure form (available at http://dx.doi. org/10.21037/apm-19-375). The authors have no conflicts of interest to declare.

Ethical Statement: The authors are accountable for all aspects of the work in ensuring that questions related to the accuracy or integrity of any part of the work are appropriately investigated and resolved. Experiments were performed under a project license (NO. 2018033) granted by The Ethics Committee of Qingdao Municipal Hospital affiliated to Qingdao University in compliance with guidelines for the care and use of animals. Animals were treated in accordance with Guide for the Care and Use of Laboratory Animals (8th edition, National Academies Press).

Open Access Statement: This is an Open Access article distributed in accordance with the Creative Commons Attribution-NonCommercial-NoDerivs 4.0 International License (CC BY-NC-ND 4.0), which permits the noncommercial replication and distribution of the article with the strict proviso that no changes or edits are made and the original work is properly cited (including links to both the formal publication through the relevant DOI and the license). See: https://creativecommons.org/licenses/by-nc-nd/4.0/.

\section{References}

1. Grant AA, Hart VJ, Lineen EB, et al. Rescue therapy for hypercapnia due to high PEEP mechanical ventilation in patients with ARDS and renal failure. Artif Organs 2019;43:599-604.

2. Tonner PH. Additives used to reduce perioperative opioid consumption 1: Alpha2-agonists. Best Pract Res Clin Anaesthesiol 2017;31:505-12.

3. Parker JC. Mitochondrial damage pathways in ventilator induced lung injury (VILI): an update. J Lung Health Dis 2018;2:18-22.

4. Bates JHT, Smith BJ. Ventilator-induced lung injury and lung mechanics. Ann Transl Med 2018;6:378.

5. Zhao C, Zhang W, Dai H, et al. Role and mechanism of Ly6C(high) monocyte in ventilator-induced lung injury in mice. Zhonghua Wei Zhong Bing Ji Jiu Yi Xue 2019;31:1123-7.

6. Mori V, Smith BJ, Suki B, et al. Linking Physiological Biomarkers of Ventilator-Induced Lung Injury to a RichGet-Richer Mechanism of Injury Progression. Ann Biomed Eng 2019;47:638-45.

7. Chen L, Xia HF, Shang Y, et al. Molecular Mechanisms of Ventilator-Induced Lung Injury. Chin Med J (Engl) 2018;131:1225-31.

8. Carvalho NC, Guldner A, Beda A, et al. Higher levels of spontaneous breathing reduce lung injury in experimental moderate acute respiratory distress syndrome. Crit Care Med 2014;42:e702-15.

9. Bhatta A, Atianand M, Jiang Z, et al. A Mitochondrial Micropeptide Is Required for Activation of the Nlrp3 Inflammasome. J Immunol 2020;204:428-37.

10. Chenery AL, Alhallaf R, Agha Z, et al. InflammasomeIndependent Role for NLRP3 in Controlling Innate Antihelminth Immunity and Tissue Repair in the Lung. J Immunol 2019;203:2724-34.

11. Tocker AM, Durocher E, Jacob KD, et al. The Scaffolding Protein IQGAP1 Interacts with NLRC3 and Inhibits Type I IFN Production. J Immunol 2017;199:2896-909.

12. Gültekin Y, Eren E, Ozoren N. Overexpressed NLRC3 acts as an anti-inflammatory cytosolic protein. J Innate Immun 2015;7:25-36.

13. Zhu H, Cao X. NLR members in inflammation-associated carcinogenesis. Cell Mol Immunol 2017;14:403-5.

14. Righetti R, Zani G, Piraccini E, et al. Lumbar UltrasoundGuided Erector Spinae Plane Block to Reduce Perioperative Opioid Consumption in Particular HighRisk Patients Undergoing Peripheral Vascular Surgery. J Cardiothorac Vasc Anesth 2020;34:1707-8.

15. Scibelli G, Maio L, Sasso M, et al. Dexmedetomidine: Current Role in Burn ICU. Transl Med UniSa 2017;16:1-10. 
16. Kim E, Kim HC, Lee S, et al. Dexmedetomidine confers neuroprotection against transient global cerebral ischemia/ reperfusion injury in rats by inhibiting inflammation through inactivation of the TLR-4/NF-kappaB pathway. Neurosci Lett 2017;649:20-7.

17. Meng PZ, Liu J, Hu PS, et al. Protective Effect of Dexmedetomidine on Endotoxin-Induced Acute Lung Injury in Rats. Med Sci Monit 2018;24:4869-75.

18. Zhang Y, Wang X, Liu Z, et al. Dexmedetomidine attenuates lipopolysaccharide induced acute lung injury by targeting NLRP3 via miR-381. J Biochem Mol Toxicol 2018;32:e22211.

19. Wu JY, Xiong ZH, Xiong GZ, et al. Protective effect of interleukin-10 and recombinant human keratinocyte growth factor-2 on ventilation-induced lung injury in rats. Genet Mol Res 2015;14:15642-51.

20. Kiss T, Silva PL, Huhle R, et al. Comparison of different degrees of variability in tidal volume to prevent deterioration of respiratory system elastance in experimental acute lung inflammation. Br J Anaesth 2016;116:708-15.

21. Wang T, Gross C, Desai AA, et al. Endothelial cell signaling and ventilator-induced lung injury: molecular mechanisms, genomic analyses, and therapeutic targets. Am J Physiol Lung Cell Mol Physiol 2017;312:L452-L476.

22. Lim RR, Wieser ME, Ganga RR, et al. NOD-like Receptors in the Eye: Uncovering Its Role in Diabetic Retinopathy. Int J Mol Sci 2020;21:899.

23. Griebel T, Maekawa T, Parker JE. NOD-like receptor cooperativity in effector-triggered immunity. Trends Immunol 2014;35:562-70.

24. Chen KW, Demarco B, Broz P. Beyond inflammasomes: emerging function of gasdermins during apoptosis and NETosis. EMBO J 2020;39:e103397.

25. Abderrazak A, Syrovets T, Couchie D, et al. NLRP3 inflammasome: from a danger signal sensor to a regulatory node of oxidative stress and inflammatory diseases. Redox Biol 2015;4:296-307.

26. Gaidt MM, Hornung V. The NLRP3 Inflammasome Renders Cell Death Pro-inflammatory. J Mol Biol 2018;430:133-41.

27. He Y, Hara H, Nunez G. Mechanism and Regulation of NLRP3 Inflammasome Activation. Trends Biochem Sci 2016;41:1012-21.

28. Song N, Liu ZS, Xue W, et al. NLRP3 Phosphorylation Is an Essential Priming Event for Inflammasome Activation.
Mol Cell 2017;68:185-197.e6.

29. Hu S, Du X, Huang Y, et al. NLRC3 negatively regulates CD4+ T cells and impacts protective immunity during Mycobacterium tuberculosis infection. PLoS Pathog 2018;14:e1007266.

30. Zha LH, Zhou J, Li TZ, et al. NLRC3 inhibits MCTinduced pulmonary hypertension in rats via attenuating PI3K activation. J Cell Physiol 2019. [Epub ahead of print].

31. Schneider M, Zimmermann AG, Roberts RA, et al. The innate immune sensor NLRC3 attenuates Tolllike receptor signaling via modification of the signaling adaptor TRAF6 and transcription factor NF-kappaB. Nat Immunol 2012;13:823-31.

32. Zhang L, Mo J, Swanson KV, et al. NLRC3, a member of the NLR family of proteins, is a negative regulator of innate immune signaling induced by the DNA sensor STING. Immunity 2014;40:329-41.

33. Uchimura T, Oyama Y, Deng M, et al. The Innate Immune Sensor NLRC3 Acts as a Rheostat that FineTunes T Cell Responses in Infection and Autoimmunity. Immunity 2018;49:1049-1061.e6.

34. Eren E, Berber M, Ozoren N. NLRC3 protein inhibits inflammation by disrupting NALP3 inflammasome assembly via competition with the adaptor protein ASC for pro-caspase-1 binding. J Biol Chem 2017;292:12691-701.

35. Hu H, Shi D, Hu C, et al. Dexmedetomidine mitigates CLP-stimulated acute lung injury via restraining the RAGE pathway. Am J Transl Res 2017;9:5245-58.

36. Zhang Y, Jia S, Gao T, et al. Dexmedetomidine mitigate acute lung injury by inhibiting IL-17-induced inflammatory reaction. Immunobiology 2018;223:32-7.

37. Meng L, Li L, Lu S, et al. The protective effect of dexmedetomidine on LPS-induced acute lung injury through the HMGB1-mediated TLR4/NF-kappaB and PI3K/Akt/mTOR pathways. Mol Immunol 2018;94:7-17.

38. Liang S, Wang Y, Liu Y. Dexmedetomidine alleviates lung ischemia-reperfusion injury in rats by activating PI3K/Akt pathway. Eur Rev Med Pharmacol Sci 2019;23:370-7.

Cite this article as: Zhang B, Zhang X, Li Q, Ma F, Sun L, Wang M. Dexmedetomidine attenuates ventilator-induced lung injury in rats by up-regulating NLRC3. Ann Palliat Med 2020;9(5):2474-2484. doi: 10.21037/apm-19-375 